\title{
Design Optimization of TIG Welding Process for AISI 316L Stainless Steel
}

\author{
Subhas Chandra Moi, Pradip Kumar Pal, Asish Bandyopadhyay
}

\begin{abstract}
AISI 316L stainless steel materials of thickness $3 \mathrm{~mm}$ have been united by tungsten inert gas (TIG) welding in square butt joint configuration as per Box-Behnken design technique of response surface methodology (RSM) to indentify the effects of input parameters on the quality of the TIG welded joints. The output responses have been measured after experimentation. Mathematical correlation between input parameters and output responses has been developed using RSM. The factors which influences on responses have been analyzed by generating the response surface and contour plots. Desirability function analysis (DFA) is employed for finding optimum parametric setting to achieve the most favourable mechanical properties. Microstructures of welded samples are also investigated to correlate the metallurgical-mechanical characteristics of the welded specimens. The result indicates that at the intermediate values of welding parameters create fine grain structure and superior mechanical properties.
\end{abstract}

Keywords: Desirability function analysis, Microstructure,.Optimization, Response surface methodology.

\section{INTRODUCTION}

TIG welding is a very much familiar and widely used fabrication technique for joining of stainless steels, aluminum and magnesium. For fabrication of light gauge metals, TIG welding is the most economic and it is extensively used in industry for very high-quality and superior welds. 316L stainless steel belongs to 300 series of austenitic stainless steel which is a renowned material for industrial applications such as heat exchangers, pressure vessels, petroleum refining equipment, petrochemical processing industry etc., because of its good corrosion resistance, formability, ductility, weldability and high tensile strength at elevated temperature compare to other stainless steels [1]. In AISI 316L stainless steel - ' $L$ ' denotes very low carbon version of austenitic stainless steel. These extra low carbons diminish destructive carbide precipitation during welding. Welding of 316L austenitic stainless steel is a complex task, due to corrosion and crack formation. The stainless steel 316L has distinct

Revised Manuscript Received on 30 July 2019.

* Correspondence Author

Subhas Chandra Moi*, Mechanical Engineering Department, Jadavpur University, Kolkata, India

Pradip Kumar Pal, Mechanical Engineering Department, Jadavpur University, Kolkata, India

Asish Bandyopadhyay, Mechanical Engineering Department, Jadavpur University, Kolkata, India

(C) The Authors. Published by Blue Eyes Intelligence Engineering and Sciences Publication (BEIESP). This is an open access article under the CC-BY-NC-ND license http://creativecommons.org/licenses/by-nc-nd/4.0/ properties, cheaper cost compared to other steel grades and welding of it is an important area of research [2-3].

Welding input variables are the key factors for obtaining the most favourable weld bead geometry or in other words, the quality of the weldment which includes hardness, tensile strength, fatigue strength etc. So, the suitable selection of the TIG welding input variables and its correct levels are very essential for achieving optimal bead geometry and mechanical properties [4-5]. To obtain good quality welds, researchers are continuously developing various statistical models to optimize welding process accurately. The experimental analysis and optimization of any welding technique is a difficult work due to very costly, time-consuming and many interlinked parameters involved while solving it. [6]. The Box-Benkhen design of RSM is a very useful technique to analysis a process effectively with reduction of cost and time, as it needs minimum (only fifteen) number of experimental runs. Desirability function analysis (DFA) is a useful optimization technique which is used for solving both single objective problems and multi-objective problems. Integrated RSM and DFA are found to be efficient for analyzing, modeling and optimization of welding processes [7].

Kiaee and Aghaie-Khafri [8] investigated the effect of welding variables on mechanical properties: joint strength, hardness etc. in TIG welding of A516-70 steel by response surface methodology (RSM). They found better output responses through experimental analysis and optimization by RSM. An experimental research had performed by Darvishmotevalli et al. [9] to optimize the parameters for chemical oxygen demand and total organic carbon removal from saline wastewater in electrochemical oxidation process using RSM. Another experimental analysis of resistance spot welding based on Box-Behnken design of RSM had been performed by Moi et al. [10]. They also utilized the applications of RSM to develop a mathematical model between input parameters and output responses. Benyounis et al. [11] developed a mathematical model and optimized laser welding parameters by using RSM technique and optimized parameters were obtained. By using these parameters they tried to improve joint quality and productivity and at the same time minimized the cost of operations. Kim et al. [12] studied MIG welding of mild steel using RSM along with genetic algorithm and DFA. They developed mathematical relation between input and output responses using RSM. In this work, the analysis has been planned to optimize the multi response characteristics: weld width, UTS and impact toughness of TIG weldment of 316L stainless steel using integrated RSM and DFA. 


\section{Design Optimization of TIG Welding Process for AISI 316L Stainless Steel}

Mathematical models have been developed for all the responses separately by RSM approach. Effect of key variables on output responses has been illustrated by response surface and contour plots. DFA has been used to predict the optimum welding condition for optimizing all the responses combinedly. Microstructures of base metal, as well as welded specimens are also examined to correlate the metallurgical-mechanical characteristics of the welded joints.

\section{RESPONSE SURFACE METHODOLOGY}

This is one of the most important and popular optimization methods in use today. It is basically an album of mathematical and statistical techniques. Modelling, optimization of engineering problems is done by this technique frequently. For three independent variables, first order mathematical model can be expressed as follows:

$Y=6_{0}+b_{1} x_{1}+6_{2} x_{2}+6_{a} x_{a}+£$

Typically, a second order polynomial equation which is used in the method of RSM as follows:

$$
\begin{aligned}
& \mathrm{Y}=6_{0}+\sum_{\mathrm{i}=1}^{k}\left(6_{\mathrm{i}} x_{i}\right)+\sum_{i=1}^{k}\left(6_{i \mathrm{i}} x_{i}^{2}\right)+\sum \Sigma\left(6_{i j} x_{i} x_{j}\right)+ \\
& \text { £ }
\end{aligned}
$$

where, $\mathrm{Y}=$ response variables

$$
\begin{aligned}
& x_{\mathrm{i}}=\text { predicted variables } \\
& \sigma_{0}=\text { constant } \\
& £=\text { random error }
\end{aligned}
$$

and $b_{\mathrm{i}}, b_{\mathrm{ii}}, 6_{\mathrm{i} j}$ are regression coefficients, where $\mathrm{i}, \mathrm{j}=1,2$, $3, \ldots . ., \mathrm{k}$.

\section{EXPERIMENTAL PROCEDURES}

AISI 316L stainless steel plates of dimensions: $100 \mathrm{~mm}$ x 60 $\mathrm{mm} \times 3 \mathrm{~mm}$ and $1.6 \mathrm{~mm}$ diameter of ER316L stainless steel filler rod have been considered for the work. Table 1 represents the chemical composition of selected base metal and filler metal. Figure 1 shows the experimental set up. Three welding input variables namely, welding current, gas flow rate (GFR) and welding speed have been selected as input welding parameters for conducting experimentation. Square butt joints have been made by semi-automatic TIG welding machine (Make - Ador Welding Ltd.). Shielding gas: pure argon has been used in this experiment. The selected input parametric settings and their levels have been given in Table 2. The experiments have been made as per Box Behnken design (Table 3) of RSM. After experimentation, output responses, UTS, impact toughness and weld width have been measured and given in Table 3

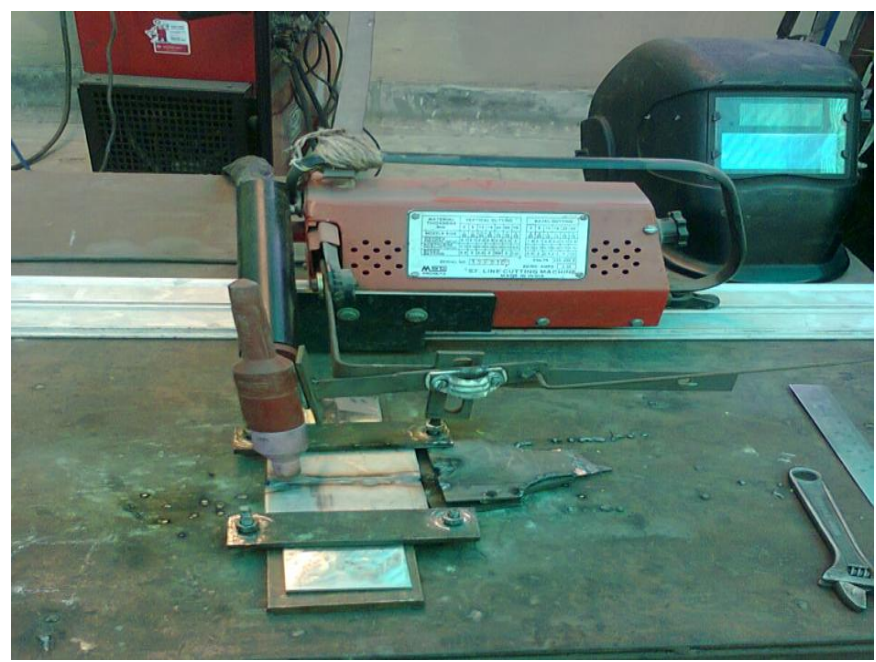

Figure 1: Experimental setup

Table 2: TIG welding input variables and theirs levels

\begin{tabular}{|c|c|c|c|c|c|}
\hline Input variable & Unit & Notatio & \multicolumn{3}{|c|}{ Levels } \\
\cline { 4 - 6 } & & $\mathrm{n}$ & -1 & 0 & +1 \\
\hline Welding current & $\mathrm{A}$ & $\mathrm{A}$ & 100 & 125 & 150 \\
\hline Welding Speed & $\mathrm{cm} / \mathrm{min}$ & $\mathrm{B}$ & 12 & 15 & 18 \\
\hline Gas flow Rate & $\mathrm{l} / \mathrm{min}$ & $\mathrm{C}$ & 6 & 9 & 12 \\
\hline
\end{tabular}

\section{RESULTS AND DISCUSSION}

\subsection{Developing the mathematical model: regression analysis}

Table 3 illustrates recorded output responses along with the experimental plan. In the present work Design Expert 11 software is used to the experimental recorded data to get the mathematical equations for weld width (WW), ultimate tensile strength (UTS), and impact toughness (IT). The developed mathematical model may be applied to predict output responses in terms of welding current, welding speed and gas flow rate.

The developed mathematical models for the responses in terms of selected input variables are as follows:

$$
\begin{aligned}
& \mathrm{WW}=6.55-0.1775 \mathrm{~A}-0.4588 \mathrm{~B}+0.1763 \mathrm{C}+0.2400 \mathrm{AB}- \\
& 0.0950 \mathrm{AC}-0.1375 \mathrm{BC}+0.2138 \mathrm{~A}^{2}-0.0237 \mathrm{~B}^{2}+ \\
& 0.1462 \mathrm{C}^{2}
\end{aligned}
$$

$\mathrm{UTS}=641.72+5.74 \mathrm{~A}+3.58 \mathrm{~B}-9.52 \mathrm{C}+4.46 \mathrm{AB}+8.85 \mathrm{AC}$ $+7.84 \mathrm{BC}-15.27 \mathrm{~A}^{2}-9.12 \mathrm{~B}^{2}-20.63 \mathrm{C}$

$\mathrm{IT}=1.33+0.6250 \mathrm{~A}+1.19 \mathrm{~B}-1.19 \mathrm{C}+2.13 \mathrm{AB}+2.37 \mathrm{AC}+$ $2.50 \mathrm{BC}-5.54 \mathrm{~A}^{2}-3.92 \mathrm{~B}^{2}-7.67 \mathrm{C}$

Table 1: Chemical compositions of base metal and filler metal (weight \%)

\begin{tabular}{|c|c|c|c|c|c|c|c|c|c|}
\hline Material & $\mathrm{C}$ & $\mathrm{Mn}$ & $\mathrm{Si}$ & $\mathrm{S}$ & $\mathrm{P}$ & $\mathrm{Cr}$ & $\mathrm{Ni}$ & $\mathrm{Mo}$ & $\mathrm{Cu}$ \\
\hline AISI 316L & 0.027 & 0.97 & 0.25 & 0.013 & 0.044 & 16.11 & 10.09 & 2.04 & 0.16 \\
\hline ER 316L & 0.041 & 1.51 & 0.46 & 0.031 & 0.031 & 18.21 & 12.01 & 2.32 & 0.76 \\
\hline Weld Metal & 0.031 & 1.41 & 0.33 & 0.021 & 0.034 & 17.23 & 10.88 & 2.23 & 0.42 \\
\hline
\end{tabular}


The sufficiency of the above said models for the various responses taken in this study is checked using ANOVA test and it is carried out at five percent significance level or in other words - ninety five percent confidence level. The results of ANOVA analysis for WW, UTS and IT are shown in Table 4. Since $P$ values for the model as well as linear terms for all the factors as shown in Table 4 are less than 0.050 , the developed models are significant. The lack of fit values for all three said models is greater than 0.05 . It means, it is not significant which is desirable.

Table 3: Experimental plan and measured responses

\begin{tabular}{|c|c|c|c|c|c|c|}
\hline Sp.No. & $\begin{array}{c}\text { Current } \\
\text { (A) }\end{array}$ & $\begin{array}{c}\text { Speed } \\
\text { (cm/min) }\end{array}$ & $\begin{array}{l}\text { GFR } \\
(1 / \mathrm{min}\end{array}$ & $\begin{array}{l}\text { WW } \\
(\mathrm{mm})\end{array}$ & $\begin{array}{l}\text { UTS } \\
\text { (MPa) }\end{array}$ & $\begin{array}{l}\text { IT } \\
(\mathrm{J})\end{array}$ \\
\hline 1 & 100 & 12 & 9 & 7.61 & 612.14 & 41.5 \\
\hline 2 & 150 & 18 & 9 & 6.35 & 631.45 & 45.5 \\
\hline 3 & 125 & 18 & 6 & 6.18 & 616.15 & 39.5 \\
\hline 4 & 125 & 18 & 12 & 6.24 & 615.21 & 42.5 \\
\hline 5 & 125 & 15 & 9 & 6.54 & 643.24 & 51.5 \\
\hline 6 & 150 & 12 & 9 & 6.78 & 615.61 & 39 \\
\hline 7 & 100 & 15 & 12 & 7.37 & 580.95 & 33.5 \\
\hline 8 & 100 & 15 & 6 & 6.81 & 620.12 & 41 \\
\hline 9 & 100 & 18 & 9 & 6.22 & 610.14 & 40.5 \\
\hline 10 & 150 & 15 & 12 & 6.82 & 609.22 & 40 \\
\hline 11 & 125 & 12 & 12 & 7.44 & 592.11 & 35 \\
\hline 12 & 125 & 15 & 9 & 6.56 & 641.77 & 51 \\
\hline 13 & 125 & 15 & 9 & 6.55 & 640.16 & 51.5 \\
\hline 14 & 150 & 15 & 6 & 6.64 & 612.98 & 38 \\
\hline 15 & 125 & 12 & 6 & 6.83 & 624.43 & 42 \\
\hline
\end{tabular}

\subsection{Effect of input variables on WW}

The combined effect among various inputs variables such as welding speed, current and GFR on the WW is illustrated in Figure 2(a) - 2(c). It is identified that as GFR increases from its lower levels to higher levels, the weld width also increases gradually. On the other hand weld width decreases progressively as welding current as well as welding speed increases simultaneously. Welding speed is found to be the most significant factor affecting weld width.

\subsection{Effect of input variables on UTS}

Figure 3(a) - 3(c) demonstrates the effect of input variables on UTS through response surface and contour plots. Here, it is noticed that, as welding current rises progressively from lower level to intermediate value, the UTS gradually attains its highest value. But when welding current increases again from middle value to its higher value, a reversed trend is observed for UTS. Almost similar patterns are also identified in case of welding speed and GFR. UTS is found to be optimum at intermediate values of welding input variables. Therefore, the study indicates that it is not suggested to use very higher or lower level of TIG welding process parameters. For UTS, GFR is the most significant factor on UTS.

(a)

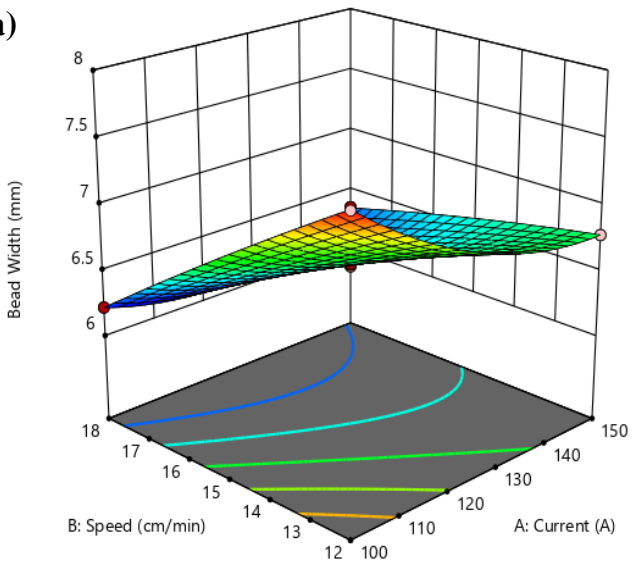

(b)
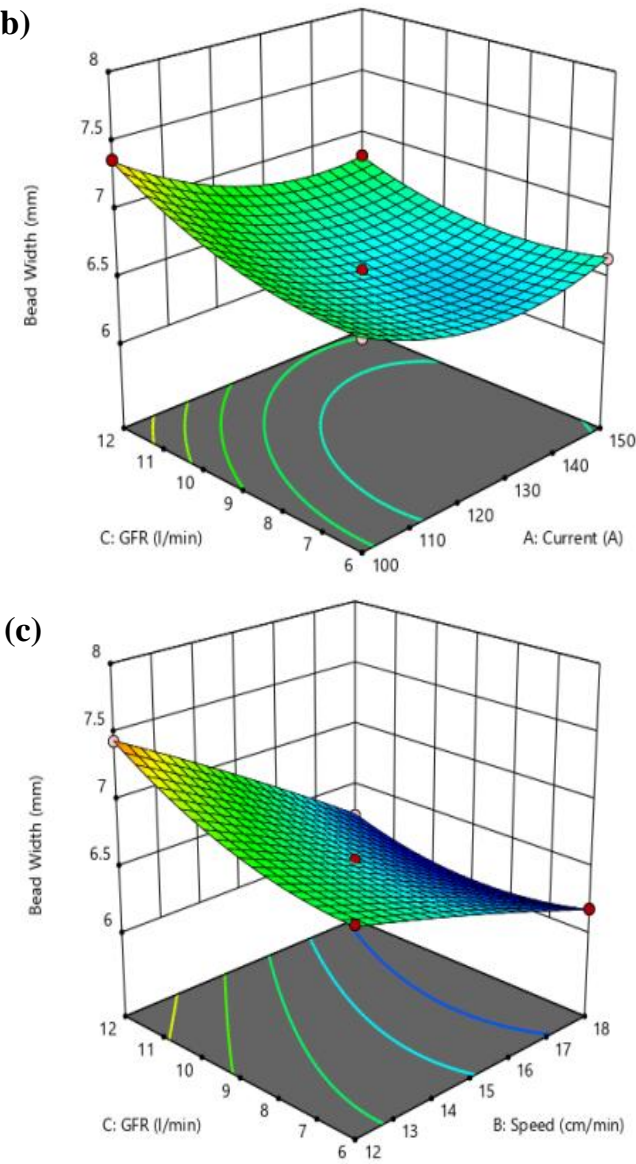

Figure 2: Response surface and contour plot showing the combined effects of (a) speed vs current, (b) GFR vs current and (c) GFR vs speed on BW 
Design Optimization of TIG Welding Process for AISI 316L Stainless Steel

Table 4: ANOVA test results for WW, UTS and IT

\begin{tabular}{|c|c|c|c|c|c|c|}
\hline Source & df & SS & MS & F-Value & P-Value & Remark \\
\hline \multicolumn{7}{|c|}{ For Weld Width } \\
\hline Model: & 9 & 2.77 & 0.3074 & 1576.48 & $<0.0001$ & Significant \\
\hline A-Current: & 1 & 0.2521 & 0.2521 & 1292.56 & $<0.0001$ & Significant \\
\hline B-Speed: & 1 & 1.68 & 1.68 & 8633.91 & $<0.0001$ & Significant \\
\hline C-GFR: & 1 & 0.2485 & 0.2485 & 1274.42 & $<0.0001$ & Significant \\
\hline Residual: & 5 & 0.0010 & 0.0002 & & & \\
\hline Lack of Fit: & 3 & 0.0008 & 0.0003 & 2.58 & 0.2913 & Not significant \\
\hline Pure Error: & 2 & 0.0002 & 0.0001 & & & \\
\hline \multicolumn{7}{|c|}{ Model Summary : $R^{2}-99.96 \%$, Adj $R^{2}-99.90 \%$, Pred $R^{2}-99.54 \%$, Adeq Precision-126.406 } \\
\hline \multicolumn{7}{|c|}{ For UTS } \\
\hline Model: & 9 & 4158.73 & 462.08 & 126.80 & $<0.0001$ & Significant \\
\hline A-Current: & 1 & 263.47 & 263.47 & 72.30 & 0.0004 & Significant \\
\hline B-Speed: & 1 & 102.67 & 102.67 & 28.18 & 0.0032 & Significant \\
\hline C-GFR: & 1 & 725.61 & 725.61 & 199.12 & $<0.0001$ & Significant \\
\hline Residual: & 5 & 18.22 & 3.64 & & & \\
\hline Lack of Fit: & 3 & 13.47 & 4.49 & 1.89 & 0.3641 & Not significant \\
\hline Pure Error: & 2 & 4.75 & 2.37 & & & \\
\hline Cor Total: & 14 & 4176.96 & & & & \\
\hline \multicolumn{7}{|c|}{ Model Summary : $R^{2}-99.56 \%$, Adj $R^{2}-98.78 \%$, Pred $R^{2}-94.58 \%$, Adeq Precision-38.508 } \\
\hline \multicolumn{7}{|c|}{ For Impact Toughness } \\
\hline Model: & 9 & 432.42 & 48.05 & 245.35 & $<0.0001$ & significant \\
\hline A-Current: & 1 & 3.12 & 3.12 & 15.96 & 0.0104 & Significant \\
\hline B-Speed: & 1 & 11.28 & 11.28 & 57.61 & 0.0006 & Significant \\
\hline C-GFR: & 1 & 11.28 & 11.28 & 57.61 & 0.0006 & Significant \\
\hline Residual: & 5 & 0.9792 & 0.1958 & & & \\
\hline Lack of Fit: & 3 & 0.8125 & 0.2708 & 3.25 & 0.2441 & Not significant \\
\hline Pure Error: & 2 & 0.1667 & 0.0833 & & & \\
\hline Cor Total: & 14 & 433.40 & & & & \\
\hline
\end{tabular}

(a)

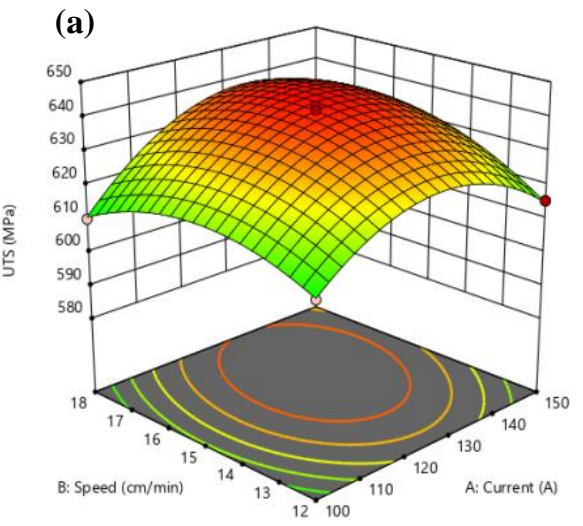

(b)

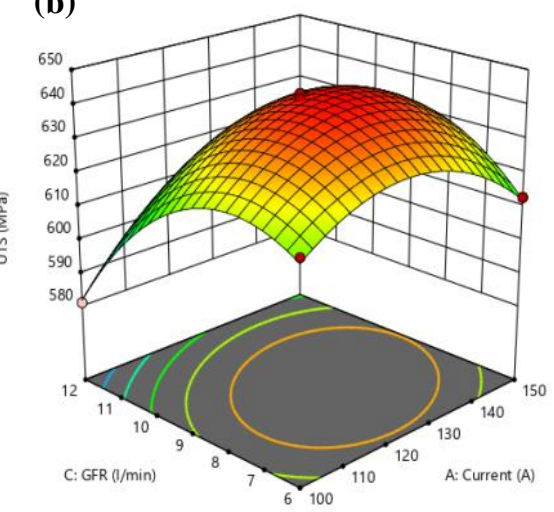

(c)

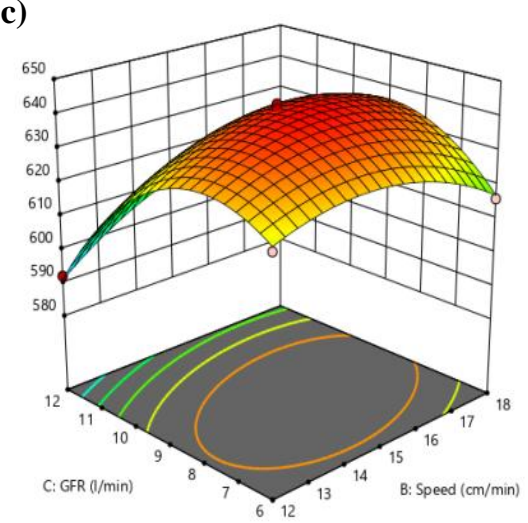

Figure 3: Response surface and contour plot showing the effects of (a) speed vs current, (b) GFR vs current and (c) GFR vs speed on UTS

the welded joints due to enough heat input and proper shielding of base materials and filler material. Impact

\subsection{Effect of input variables on impact toughness}

3D response surface and contour plots for the response IT illustrates in Figure 4(a) - 4(c). The medium values of welding speed and GFR result optimum value of impact toughness of toughness rises with current up to an utmost value and thereafter it stars decreasing rapidly. 
(a)

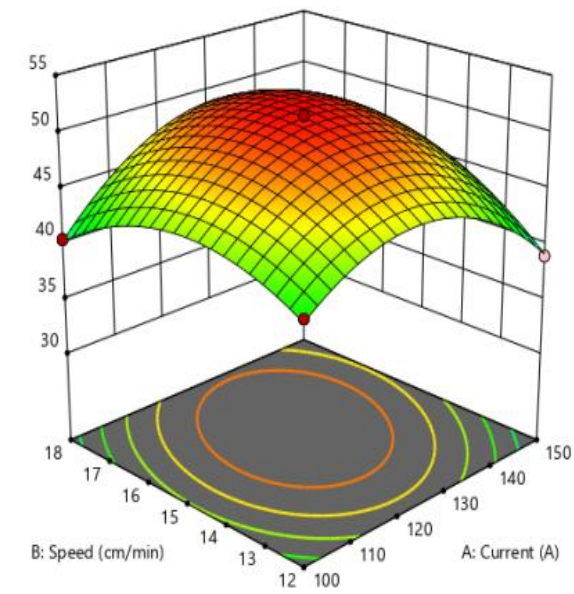

(b)

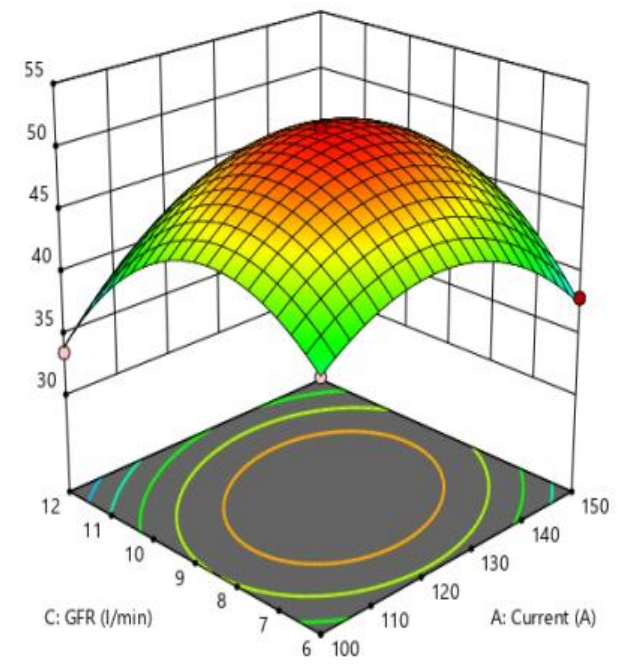

(c)

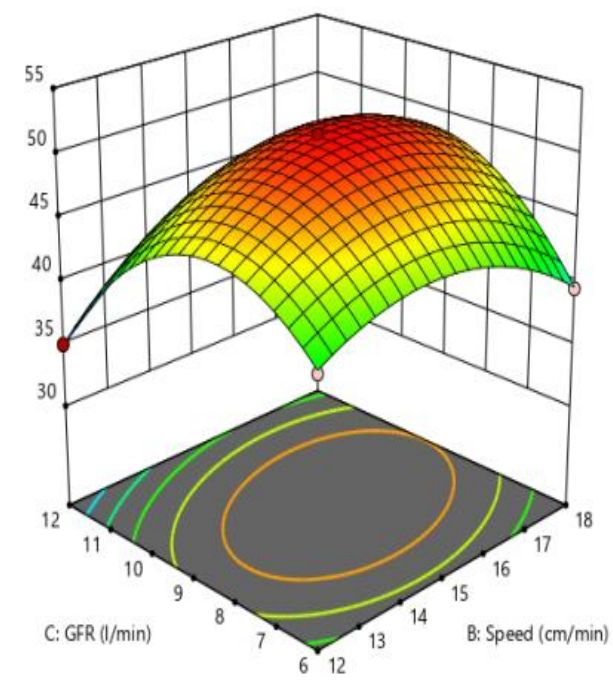

Figure 4: Response surface and contour plots showing the interaction effects of (a) speed vs current, (b) GFR vs current and (c) GFR vs speed on impact toughness

\subsection{Micro structural analysis}

Three welded joints namely sample no. 5, 6 and 7 along with base material have been prepared for microstructural inspection which is performed by the technique of scanning electron microscopy (SEM). The criteria of selection of these specimens for micro structural study is based on the obtained responses i.e. the specimens having maximum, average and minimum mechanical properties (UTS and IT) respectively.

The quality of weldment is mainly controlled by the solidification behaviours of the weld metal. It manages weld metal microstructure, grain structure, mechanical properties etc. The solidification mode of weld metal can be explained by the $\mathrm{Cr}_{\text {eqv. }} / \mathrm{Ni}_{\text {eqv }}$ ratio [13]. Nickel and chromium equivalents can be obtained based on the chemical composition of the examined weld metal. The $\mathrm{Cr}_{\text {eqv. }} / \mathrm{Ni}_{\text {eqv }}$ ratio is calculated using the Schaeffler formula [14] given below:

$C r_{\text {eqv. }}=\mathrm{Cr}+\mathrm{Mo}+1.50 * \mathrm{Si}+0.50 * \mathrm{Nb}$

$N i_{\text {eqv. }}=\mathrm{Ni}+30 * \mathrm{C}+0.50 * \mathrm{Mn}$

In the present study the $\mathrm{Cr}_{\text {eqv. }} / \mathrm{Ni}_{\text {eqv }}=1.60$ (composition of weld metal is listed Table-1). So, the solidification mode is ferritic-austenitic mode (FA) $\left(1.48 \leq C r_{e q v .} / N i_{e q v} \leq 1.95\right)$.

$$
\begin{gathered}
\text { Mode FA: } \mathrm{L} \rightarrow \mathrm{L}+\delta \rightarrow \mathrm{L}+\delta+\gamma \rightarrow \delta+\gamma \rightarrow \gamma: \\
1.48 \leq \mathrm{Cr}_{\text {eqv. }} / \mathrm{Ni}_{\text {eqv }} \leq 1.95
\end{gathered}
$$

where, $\mathrm{L}$ is the liquid, $\delta$ is delta-ferrite and $\gamma$ is austenite respectively.The SEM microstructures of base metal and weld metals of sample no. 5, 6 and 7 is shown in Figure 5.

Completely austenitic structures along with few annealing twins are found in the microstructure of base metal and the weld metals consist of ferrite and austenite. The weld zone of sample no. 5 exhibits a very fine skeletal $\delta$-ferrite along with grain, subgrain and migrated boundaries in plain austenitic matrix due to moderate heat input and moderate cooling rate. The weld metal of sample no. 6 exhibits a coarse equiaxed grains structure which is generated due to the decomposition of dendritic grains in plain austenitic matrix and sample no. 7 consists of ferrite in the form of dendritic lathy $\delta$ ferrite at the dendrite core bounded by inter dendritic $\gamma$-phase due to low heat input.

\section{MULTI-OBJECTIVE OPTIMIZATION USING DFA}

The desirability function analysis is one of the most vital and extensively utilized techniques for the optimization of various responses. In the study the multi object optimization of TIG welded 316L stainless steel is carried out. The desirability function analysis is applied to get an optimum parametric setting to achieve minimum weld width, maximum UTS and maximum IT of TIG welded samples simultaneously which is most wanted for high-quality welded joints. Minitab v17 software is applied on the obtained experimental data to optimize TIG welding process. The usual steps and procedures are followed which is incorporated in Minitab software, the details of these are omitted here. The results of multi objective optimization for BW, UTS and IT are shown in Figure 6. The value of

composite desirability factor $\mathrm{D}$ is 0.961.Therefore the obtained optimized TIG welding input variables can be considered to achieve optimum weld bead geometry 
and mechanical properties on 316L austenitic stainless steel.
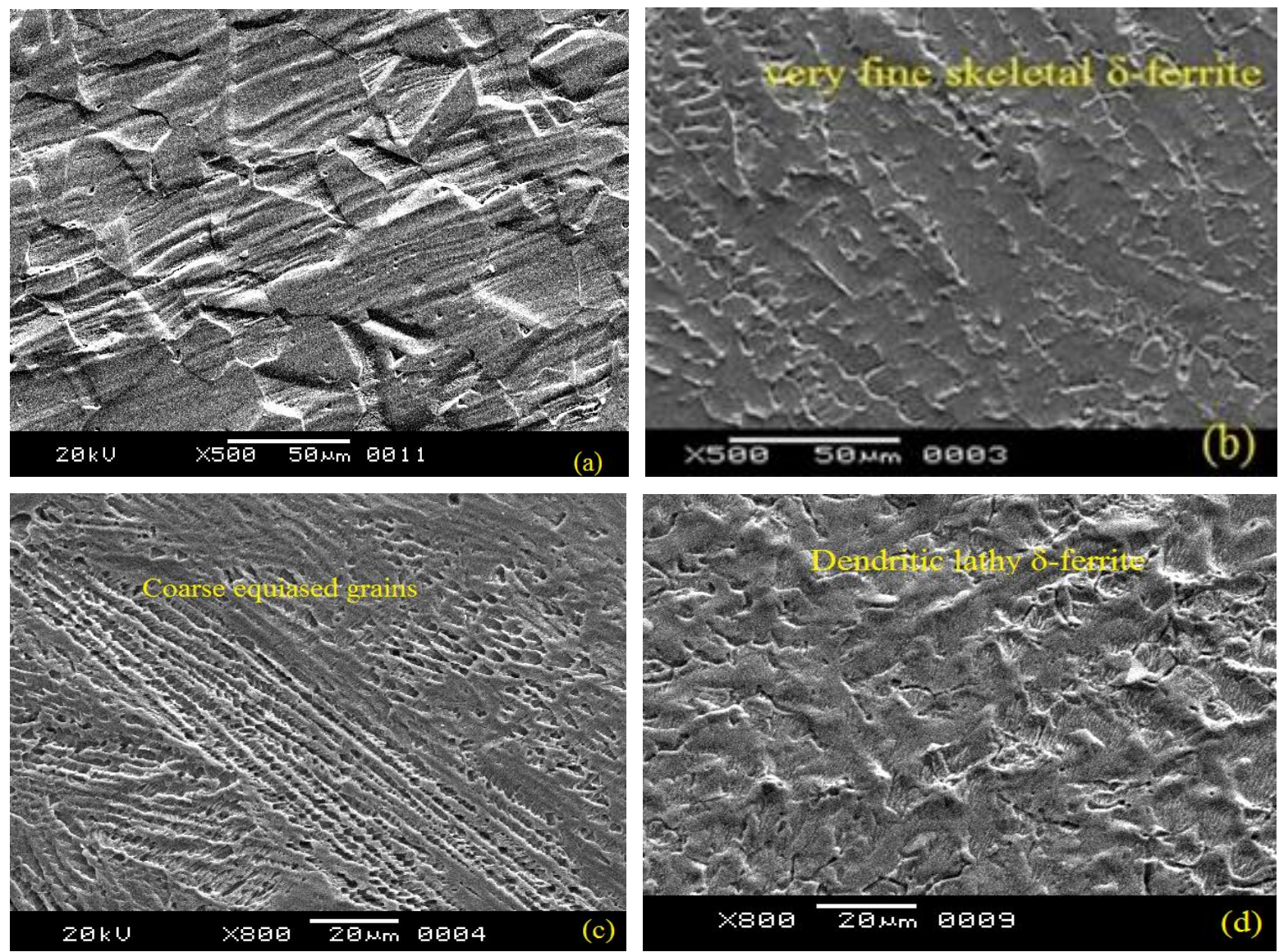

Figure 5: SEM micrographs of (a) base metal (b) sample-5 (c) sample-6 and (d) sample-7

\subsection{Confirmation test}

Confirmatory tests are also performed to validate the results of optimization obtained from the developed models. A set of three confirmatory tests have been performed at the optimized parametric setting. Table 5 shows the result of confirmatory test. It is observed from Table 5 that there is very small (less than 2\%) error between the predicted and experimental results. And it is within the satisfactory range of percentage errors.

Table 5: Result of confirmatory tests

\begin{tabular}{|l|l|c|c|c|}
\hline Optimum & & \multicolumn{3}{|c|}{ Responses } \\
\hline condition & $\mathrm{A}=129.29$ \\
$\mathrm{~B}=16.85$ & & WW & UTS & IT \\
\cline { 2 - 5 } & Avg. Actual & 6.38 & 650.52 & 51.60 \\
\cline { 2 - 5 } $\mathrm{C}=8.91$ & Predicted & 6.26 & 641.55 & 50.87 \\
\cline { 2 - 5 } & $\mid$ Error \% & 1.92 & 1.39 & 1.44 \\
\hline
\end{tabular}

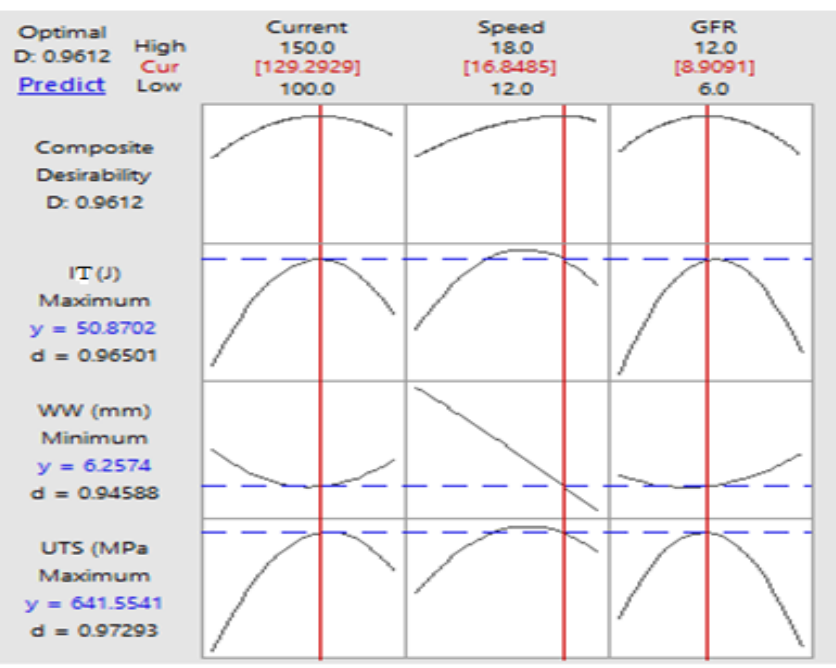

Figure 6: Optimization results of WW, UTS and IT

\section{CONCLUSIONS}

The conclusions which are drawn from the experimental results, their interpretations and analyses, are as follows:

1. The most significant factor affecting UTS is gas flow rate. Next significant factors in this respect are welding current and welding speed respectively.

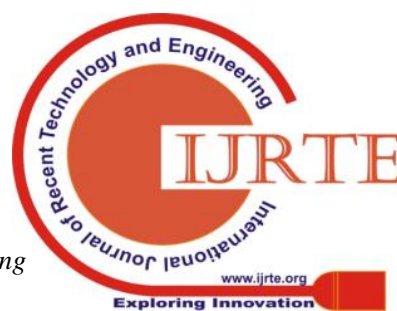


2. In case of weld width, welding speed is the most significant factor affecting it.

3. Welding speed and GFR have equal contribution affecting impact strength.

4. The weld metals with moderate heat input exhibit very fine skeletal $\delta$-ferrite and with low heat input exhibit dendritic lathy $\delta$-ferrite structure in plain austenitic matrix.

5. The optimum welding combination for optimizing all the responses simultaneously obtained by desirability function approach is: current $=129.29 \mathrm{~A}$, speed $=16.85$ $\mathrm{cm} / \mathrm{min}$ and gas flow rate $=8.91 \mathrm{~cm} / \mathrm{min}$, and predicted UTS $=641.55 \mathrm{MPa}$, impact strength $=50.87 \mathrm{~J}$ and weld width $=6.26 \mathrm{~mm}$.

6. The error between the predicted results and the results of confirmatory test is found less than $2 \%$ which validates the applied optimization technique.

\section{REFERENCES}

1. S. C. Moi, A. Bandyopadhyay, P. K. Pal, "Parametric Optimization of TIG Welding Process on Mechanical Properties of 316L Stainless Steel Using RSM," Selected Contributions from the First International Conference on Mechanical Engineering, Jadavpur University, India, 2019, pp. 315-336. DOI: 10.1007/978-3-319-96968-8_15.

2. G. I. Khidhir, S. A. Baban, "Efficiency of dissimilar friction welded 1045 medium carbon steel and 316L austenitic stainless steel joints", J. Mater. Res. Technol., vol. 8(2), 2019, pp. 1926-1932.

3. L. Chen, G. Mi, X. Zhang, C. Wang, "Numerical and experimental investigation on microstructure and residual stress of multi-pass hybrid laser-arc welded 316L steel," Materials and Design, vol. 168, 2019, pp. $1-12$.

4. Choudhary, M. Kumar, D. R. Unune, “Experimental investigation and optimization of weld bead characteristics during submerged arc welding of AISI 1023 steel”, Defence Technology, vol. 15 2019, pp. 72-82.

5. W. A. Ayoolaa, W. J. Suderb, S. W. Williamsb, "Effect of beam shape and spatial energy distribution on weld bead geometry in conduction welding”, Optics \& Laser Technology, vol. 117, Sept. 2019, pp. 280-287.

6. Ruggiero, L. Tricarico, A. G. Olabi, K. Y. Benyounis, "Weld-bead profile and costs optimisation of the $\mathrm{CO} 2$ dissimilar laser welding process of low carbon steel and austenitic steel AISI316", Optics \& Laser Technology, vol. 43, 2011, pp. 82-90.

7. D. De, T. Nandi, A. Bandyopadhyay, "Parametric study for wire cut electrical discharge machining of sintered titanium", Journal of Mech. Engg - Strojnícky časopis, vol. 69(1), 2019, pp. 17 - 38.

8. N. Kiaee, M. A. Khafri, "Optimization of gas tungsten arc welding process by response surface methodology", Materials \& Design, vol. 54, 2014, pp. 25-31.

9. M. Darvishmotevalli, A. Zarei, M. Moradnia, M. Noorisepehr, H. Mohammadi, "Optimization of saline wastewater treatment using electrochemical oxidation process: Prediction by RSM method", MethodsX, vol. 6, 2019, pp. 1101-1113.

10. S. C. Moi, P. K. Pal, A. Bandyopadhyay, R. Rudrapati "Determination of tungsten inert gas welding input parameters to attain maximum tensile strength of 316L austenitic stainless steel", Journal of Mech. Engg - Strojnícky časopis, vol. 68(3), 2018, pp. 231-248.

11. K.Y. Benyounis, A.G. Olabi, M.S.J. Hashmi, "Optimizing the laser-welded butt joints of medium carbon steel using RSM", Journal of Materials Processing Technology, vol. 164-165, 2005, pp. 986-989.

12. D. Kim, S. Rhee, H. Park, "Modelling and optimization of a GMA welding process by genetic algorithm and response surface methodology", Int. J. Prod. Res., vol. 40, 2002, pp. 1699-1711.
13. J. C. Lippold, D. J. Kotecki, "Welding metallurgy and weldability of stainless steels", 1st edition, John Wiley \& Sons Inc, 2005.

14. S. Kou, "Welding metallurgy", 2nd edition, John Wiley \& Sons Inc, 2003. 